\title{
A Power Transitions Perspective on Economic and Educational Equity: An Unfolding Epilogue for the Arab Spring?
}

\author{
James Barbre \\ School of Education, Indiana University East \\ 346 Tom Raper Hall, 2325 N. Chester Blvd, Richmond, Indiana, United States
}

Tel: 1-765-973-8344Ｅ-mail: jbarbre@iue.edu

Received: January 6, 2012 Accepted: February 19, 2012 Published: March 1, 2012

doi:10.5296/ije.v4i1.1245 URL: http://dx.doi.org/10.5296/ije.v4i1.1245

\begin{abstract}
The events of the Arab Spring have not unfolded in any final sense. As a result, social forces are moving across North Africa and the Middle East and compelling a close look at the precedent that nations have lived under. As a result of this re-examination, the social roles held by men and women are one of the many issues being looked at closely. The sense of social empowerment that will result and manifest within the national mindset is one that will challenge the precedent of a patriarchal mindset. Utilizing Power Transitions Theory as a lens through which to view Neo-Realism and social change, the argument will be made that it is in the best interests of every citizen within these separate nations to embrace educational and economic equity for women.
\end{abstract}

Keywords: Power Transitions Theory, Arab Spring, Gender Roles, Equity, Economics, Education, Precedent, Satisfaction and Dissatisfaction 


\section{Introduction}

Events which began in Tunisia, but worked their way across North Africa and the Middle East are extraordinary to say the least. While the sentiments that inform many of the protests or conflicts at present were certainly simmering under the surface, the ultimate manner in which they will play out is not entirely clear from one nation to the next. A key set of issues that each country, regardless of the leadership, will be forced to take a more detailed examination of is that of precedent. In the context of the Tunisian Genesis Event, existing precedent has been shown to blatantly favor the few over the many. This precedent is not relegated to Tunisia, but is widespread across the region. This sense of precedent and the various cultural forms it takes is the subject of this analysis.

The concept and problem of precedent to be examined here is the ways in which societies and their culture re-invent themselves following a period of upheaval. History has shown that some groups forge ahead in a progressive sense, while others rely on conservative forms of historic nostalgia. As a result of this nostalgia, the roles and rights of many citizens can be marginalized or simply ignored.

The conceptual framework to be utilized for this analysis is that of Power Transitions Theory (Tammen, et al, 2000). The assumptions behind this theory are that as the locus of power shifts within a nation or a region, be it economically socially or politically, the different systems that nations use to it uses to organize themselves are thrown into flux. These are the characteristics of structure, dynamics, and policy (p. 5). Ultimately, the manner in which these characteristics are delivered by the various institutions to different populations will have outcomes that promote satisfaction or dissatisfaction on the part of members of the population. As institutions or individuals make the decisions that affect domestic and international policy, the outcomes of these decisions will promote a mindset that is either accepting or antagonistic. This mindset is oriented around the nature of satisfaction and dissatisfaction. One perspective (satisfaction) seeks to accept decisions made at higher policy levels, whereas the other (dissatisfaction) seeks to reject and eventually change them.

This analysis will consist of a description of Power Transitions Theory and the manner by which it relates to educational equity for women. Waltz's Theory of Neo-Realism will be used as a lens to examine the structural results of this asymmetric state of power and influence will be weighed against changes that have occurred through North Africa and the Middle East as they are reflected societally and through the results of polls that address public opinion as they are reflected in the Arab Human Development Report (2005 \& 2009). For purposes of this analysis, the data gathered through these reports will apply to nations whose populations have in some way, regardless of the percentage of the participants, risen up and advocated for change. While the Arab Spring is certainly a fluid movement on many levels and will remain so for some time to come, fifteen nations will comprise the units of analysis here. Finally, the conclusion will argue that educational equity presents a natural manifestation of basic human rights that are good for all people and, consequently, the populace of any nation.

Power is a central component within P-T theory as it ultimately determines the ability of the 
governing authorities within a particular governmental unit, be they political or economic, to extract products from their subjects through the results of work (Tammen et al, 2000, p. 8). As the power shifts, the dynamics of who is or becomes the ruling authority is brought into question. Sometimes the players will change and other times they will change the policies they use in order to continue their influence over their respective populations.

Precedent, which is a constituent component and result of the decisions by those in power can be a difficult set of social mores to break, especially when it is informed directly by cultural tradition. The precedent that women are confined to a particular role is one that is historically rooted in nations throughout the world. While women have certainly made breakthroughs at many different levels in the private and public sector throughout the world, there is still much progress to be made.

The central set of issues to be addressed here is the relationship between educational equity and the eventual economic outcomes that arise from access to that equity. Educational equity has always been a noble goal. As schools are generally institutional in nature, they will impart a particular code of cultural and social values to students. In some nations, such as the United States, this form of civics education is what educates the younger generations as to what is expected of them as productive citizens. This knowledge is based on what has occurred historically and also the notable figures or events within that nation's history. This canonized approach to civic inculcation reproduces, for the most part, the subsequent cultural and social mores of the target group. It instills the pro-active mindset of patriotism and the reactive forms of national pride. Precedent therefore is a monolith all by itself.

As a default result of education, precedent also greatly determines the capabilities of the respective economy through the civic sensibilities or personal/professional ambitions of graduates seeking further study or employment following their schooling. This applies to roles within the workforce through knowledge imparted to students, both in terms of their current reality and future possibilities. This is the essence and result of human capital investment. In an inevitable sense, this will have a determining effect on what the national labor force is able to produce or contribute to the world economy. While every nation can go past the limitations of the present day if they desire to, the complicating variable here is that this potential national or social evolution runs into those parties or precedents currently in power. This is quite lucid in seeing the throngs of people in Tunisia, Egypt, Syria, Libya, Bahrain, Algeria, Jordan, Saudi Arabia, Oman, and other places clash with the set of precedents that have shackled them for years.

In the Arab world, as with many other regions, gender equity in education has not been a priority historically. As a result the workplace has not afforded women the same opportunities as men, en masse. The aim of this analysis is to examine the ultimate effects on competitiveness through this approach and illustrate the results, both within and outside national borders. Utilizing P-T Theory as a conceptual lens along with information on certain Arab and North African nations, the argument will be made that the Arab Spring represents a movement that is both long overdue and an opportunity to be a catalyst toward change that is both long-lasting and equitable. 
The challenge confronting societies and their schools in the present globalized and interdependent economies is not only the best manner of necessary investment in their own human capital, but also to whom the opportunities arising from that investment should apply to. As events brought about through the Arab Spring continue to illustrate that when the dust settles, a nation must decide which direction it will go in. The tension left behind pulls in either the traditional (and more restrictive) direction versus that of the progressive (opening more opportunities) way of thinking.

Power transitions theory is a framework developed for understanding international relations between countries and/or regions of the world. In the end, every nation is concerned with its own interests. Individuals within that nation and the ways in which they are arranged and work give it its collective sense of legitimacy and external influence with regard to other nations. This set of relations certainly has civic and national implications, but also educational.

Power Transition (P-T) Theory applies to the outcomes of school and education when viewed from a human resource perspective in that people are better able to work and raise their standard of living when they are better educated and, more importantly, when that education is met with genuine opportunities in the workplace. These contributions are apparent in their ability to achieve through skilled labor, professional or managerial competencies the next generation of new knowledge and/or products and services for themselves and/or other to consume. By achievement, I refer collectively to raising the standard of living for the population and the level of influence a nation has regarding global trade. The degree of this accomplishment depends on the talent that is cultivated through the education of their populace and the ability of people to introduce those talents into the workforce.

Achieving economic parity through equity in education forces groups or cultures to confront the traditional boundaries and social roles that have been historically built into the means they use to navigate and make sense of their world and the global landscape. This most aptly applies to women who are often forced to take the proverbial 'back seat' with regards to developing their own potential through formal and informal education. In this way, power transitions theory addresses substantial dimensions of structuralism in the ways it addresses the relationships between different individuals or groups and the larger population to which they belong (Baronov, 2004). This occurs at numerous levels, of which national and ethnic are but two.

\section{Power Transitions Theory, Culture, and Education}

Power Transitions Theory always describes a structure, or hierarchy, of some sort. In conventional terms, a hierarchy refers to the established structure and operation of entities, be they governmental or private. Within the structure and operation of entities, particular individuals or parties occupy positions of greater power. From there they influence the policy and actions that result. Groups or individuals of lesser power and influence serve the function of reinforcing and carrying out those policy and action decisions. An example of this would be policy decisions that occur at the federal or state level with regard to educational outcomes. As the elite makes policy decisions, it becomes the responsibility of 
the subordinates to carry them out. If they do not, then they are eventually removed from the particular entity within which they work. For purposes of this analysis, a fundamental assumption is that a vast majority of hierarchies are oriented around a patriarchal model. Schools reflect such hierarchy in the manner of their decision-making and priority setting.

The second feature of P-T Theory is that it describes a particular set of dynamics, or power. In attempting to narrowly define what power is, it is necessary to describe some of the components that inform and sustain it. "Power is defined as the ability to impose on or persuade an opponent to comply with demands" (Tammen et al. 2000, p. 8). In terms of international relations and the interactions between the population(s) of different countries, power has three features by those who hold it: (1) the number of individuals who can fight or work, (2) the economic productivity they present, and (3) the effectiveness of the political system in extracting and pooling individual contributions to advance national goals (p. 8). On the national level, this applies directly to the different roles that people are permitted to either hold or to envision themselves ascending to. Thus, to say that some positions are for men and others are for women becomes the result of the images reflected through existing power structures.

Through time, better educational and workforce access in Western democracies has re-formulated the acceptable roles for members of society (Douglas 1995). Historically, it has played to their economic advantage. In equalizing access to education, contemporary societies benefited both economically and in terms of their own forms of societal evolution. In viewing the educational policies from one country to another, it is reasonable to conclude that people from one nation will come to wish their own lot in life to be improved if they see that people from another nation have advantages and other benefits that they lack. Those who come to wish for this improved lot in life are generally lower on the socioeconomic strata and less powerful than those at the top. People or parties in power are quite often more interested in maintaining the influence their own positions, rather than effecting real change.

The third and final feature of power transitions theory is that of policy. In this context, it is necessary to evaluate policy not only in terms of its intent, but more importantly the outcome(s). Levels of satisfaction and dissatisfaction resulting from hierarchical decisions regarding who may hold particular positions of power and influence within the workforce and the degree of social mobility they have. These decisions directly impact members of the population, especially on the lower rungs of the particular society. It is within this context that the shortcomings of a strict patriarchal system are clearest. Nations with greater or full access for women to education and opportunities within the workforce see the benefits of a diversified approach and a larger pool of talent. This directly affects the standard of living of the particular nation and its ability to project its influence beyond its own border.

The outcome from social and other interactions between members of a population are certainly multifaceted, but may be broken down into categories of satisfaction/dissatisfaction as they relate to structure, dynamics, and policy (Tammen et al. 2000). By satisfaction and dissatisfaction, this means that the context of one's experience, or wherever they should 
happen to live, will bring about different perceptions of self-efficacy and the effects it has on pride and motivation. Pride and motivation become important catalysts in that they may serve as the driving force to better ones self through future work or study. When people or parties see others and see that their quality of life is greater than their own, cross-border envy can be the result. In the sense of not being able to achieve the same level of satisfaction as their neighbor, they may become less enthusiastic about what they are able to accomplish themselves and so contribute less toward their own or the general social or economic efforts of their nation.

\section{Educational and Human Resources: Satisfaction and Dissatisfaction}

Education is perhaps the fundamental means by which societies invest in their own human capital and subsequent development. This development is both social and economic, and from a human capital perspective, educationally-situated. They will be more apt to change their policies if they see greater collective benefits. Ilon (1998) asserts that "the globalization of the world's economies affects both educational supply and demand" (p. 347). Going further, "Since the global economy has meant enormous changes in labor markets, educational demand has also changed" (p. 347). This further illustrates the collective burden imposed by a patriarchal model of operation.

Access to higher levels of education is restricted to fewer and more selected people and so lack the greater efficiency to be more competitive. As a result, the less-powerful members of society and predominantly women stand a much greater chance of being forced into more menial roles as working members of society. If the nation is able to increase its productivity and level of competitiveness in spite of this prejudice, it comes about through purposeful, yet arbitrary, social sorting and the race to catch up or simply keep up does not concern itself with educating or cultivating talent, but rather filling needed working roles with "able bodies".

In nations known for cheap labor and the ability to do little more than fill the orders of richer economies, the need for investment in human capital is not absent. Citing Wood (1994), Burtless (1995) reports that even nations which offer a cheap source of labor are finding that demand for education has at least risen to moderate levels, thus reflecting the shift in skill sets which occurs as economic development continues. In response to the forces of globalized and decentralized economies, the educational systems of different nations are responding to realistic challenges by educating students in their schools to be more knowledgeable and competitive in the workforce. Cummings (1995) argues that this is due partly to the cost of living, but more importantly due to the continual needs involved in economic growth and development and in international competition.

An additional and no less relevant dimension of satisfaction and dissatisfaction arises through the media and images, which are distributed to and consumed by people in the world. People who view these images of a better life or a greater degree of self-determination are quite likely to be desirous of them. Regardless of differences in culture, the essence of realizing ones own potential can be intoxicating to take in. 


\section{Macrothink}

International Journal of Education

ISSN 1948-5476

2012, Vol. 4, No. 1

The massive dominance and distribution of western media forms present an ongoing test of cultural mores to non-western cultures, which consume the images. Through exposure to the sheer volume of alternative social roles and options, there is a greater degree of probability that marginalized groups will seek change through the awareness of inequality. They may seek to become more collectively organized and powerful and enact social change. One only has to research areas of human rights abuses to see outcomes within a particular nation and the resulting opinions and policies that will occur with other nations. As noted in the Arab Human Development Report's section on governance, "Any society is only as free as its media is" Arab Human Development Report Press Kit (Chapter 8 Section 3). It is natural to see the possibly precarious position that schools might occupy here. They could be made to serve as agents of change or sites of conservative resistance; depending on the influences to which they are subject.

Every nation that relies on the abilities of members of its population to help it become or remain competitive requires increasingly higher levels of sophistication within the educational system. From a power transitions perspective, the lack of efficient educational sophistication would likely lead to a sense of dissatisfaction for members within the workforce. If they cannot attain the level of satisfaction at home, they will, if able, be more likely to try and go abroad to obtain it. This can occur through seeking employment outside their native country or a program of education. In terms of education, this has the economic benefit in obtaining greater skills and bringing them home to use. The experience of education will not strictly stop there. The cultural exposure outside their own country has a greater chance to present opportunities for them to see contradictions in what they had previously accepted or taken for granted. This presents the possibility of becoming dissatisfied with the way things are at home through an increased awareness of how other people or cultures live. This may affect their perception of the existing international order and the economic and social place their nation occupies in it. They may come to see the fact that their nation or economy is less than what it could be due primarily to bad policy decisions. This awareness may be triggered through an awareness of caste, religious, political, or as is the focus of this analysis: gender inequality.

\subsection{Collective Results of Exclusion}

When the exclusion of women occurs through education or their limited contribution to the workforce, this is like trying to perform a difficult task requiring two hands while having one hand tied behind the back. Leach (1998) writes that within the strict patriarchal model, those"...who fill most civil service posts continue to maintain age-old traditional attitudes regarding appropriate male and female roles in society" (p. 13). The dispositional mindset here is not one that is progressive by nature or design. Ultimately, the decisions that keep certain parties or ideas in power have outcomes that affect everyone. Thus, it is in a nation's own best interests if they critically analyze the ultimate results of the traditions by which they have chosen to operate historically.

Hunt and Posa (2001) refer to some of the benefits that improved gender status can have within a culture with wide-ranging examples from South Africa to Colombia to Sudan to 
Ireland to Israel and the like. The changes they describe had their effect on a society-wide scale with some improvements being economic, while others were political. The presence of improved gender equity was, therefore, multifaceted. In each of these particular situations, the increase social roles of women were substantial and, at the same time, entirely pragmatic within the culture(s) in which they occurred. From humanitarian efforts in war-torn countries like Sudan and Colombia to the founding of the Northern Ireland Women's Coalition (NIWC), a political party in Northern Ireland, that had a substantial impact in the drafting of the Good Friday Agreement. Both Israeli and Palestinian women have formed groups that voice concerns and beliefs, political and otherwise, in ways that are organized, consistent and non-violent. The authors, therefore, assert that women have more effective strengths to contribute to the problem-solving efforts of difficult situations than many men, due to the fact that, depending on class-status, they have historically had less power in many countries/regions of the world in the first place (Hunt and Posa, 1997, p. 201). It is natural to conclude that the mindset they bring to a particular situation is more dynamic and prone to "thinking outside the box". For this reason, they also assert that women would be endowed to think more creatively in overcoming obstacles than men in many situations.

Mitter (1999) asserts that, globally speaking, women are continually entering the workforce in increasing numbers and in a variety of capacities. This provides a vital component for the success of the economy of a country. Women are mostly relegated to lower levels on the hierarchical business and corporate structure and without their presence at all levels, the workforce does not possess necessary adaptive fortitude. Mitter also relates the increase in foreign direct investment in regional economies where women have a greater presence. In its own right, this makes for a conclusive argument in favor of increased education and the natural abilities it increases. In areas such as East and Southeast Asia, Eastern Europe and Central Asia, Sub-Saharan Africa et al, the investment many times quadrupled and the net private capital flows increased proportionately. In regions where women were prohibited from increased or substantial participation in the workplace, the investment and capital flows remained stalled by comparison. It is logical to conclude that if greater steps were taken in pursuing educational equity for both sexes, the same benefits would occur, but at a higher level, both economically and socially. According to Benavot (1992, p. 5)

...it is received wisdom that national variations in the composition of official and implemented curricula, by their influence on student achievement levels, have important long-term effects on the quality and productivity of the labor force and, consequently, on a nation's competitive position in the world economy.

\subsection{Prejudicial Tendencies}

Kenneth Waltz $(1976,1986)$ asserts that within any national or international system, there are fundamental characteristics that influence the workings and exchanges that occur between members of different constituencies. These characteristics are propagated by institutions that are endowed with the legitimacy or power to shape policy. The results of these decisions and their effects on social, economic or other policies are referred to as ordering principles. This also involves educational practices and the outcomes create a segment of the population 
with greater sway over other through the sheer exposure to resources, of which education is but one. This regards the skills, knowledge, and values imparted through schooling.

The eventual outcomes of educational policy coincide with the assertions of power transitions theory. The fact that the schools reproduce a particularized set of beliefs within the social fabric becomes important as a part of this system. The leadership of the system is concerned with maintaining a particular form of social cohesion, while at the same time, being able to extract certain resources from its population to accomplish educational, economic, or social ends.

The nature of economic competition between nations and the need to further develop investment in human capital through education will produce a level of satisfaction or dissatisfaction. Satisfaction or dissatisfaction is produced through adhering to the need to change or ignoring it and so affecting the lives of those who would access education in order to better themselves. The results of this hold very real consequences for nations desiring to participate in and profit through trade and commerce, but are unable to do so because they lack the general talent. This talent is not to be found strictly within higher echelons of government or industry, but at all levels of the country's economy. As people navigate this environment, they are exposed to interactions that illustrate to them, implicitly and explicitly, their place within a particular community. Marginalization and exclusion in any environment has a damaging influence and it is made worse when these influences are systemic in nature and work to the disadvantage of a large segment of a group, as in the case of women.

Gender equity comprises a vital variable in achieving parity between economies on local, national, and international scales. This is important not only for raising global living standards, but in further developing individual rights. Education is a natural dimension of this.

\section{The Cultural Component}

Culture is a learned system of values and not one that is genetically inherent. When cultural frameworks advance the right or standing of men over women, this occurs in a variety of ways, of which educational equity is but one. Educational "equity considerations make important the provisions of learning opportunities for groups previously denied access to primary schooling... and, in many instances, women and girls" (Jones, 1997, p. 370). This is due to the successful propagation of patriarchal control within institutional settings. It is a system of socially programmed roles whereby different parties recognize through encouragement or coercion, the legitimacy of particular structures of authority around them and to which they are subject. Marquadt and Engel (1993, p. 19-23) frame culture within specific categories as they relate to particular groups or individuals. While these categories are certainly broad and overlapping, there are important distinctions between them.

- Religion

- Level of education and educational practices

- Economics 
- Politics

- Family structure

- Class structure

- Language

- History

- Natural resources/geography

In the case of exploited groups, each of these features of culture plays an important role in how women or other less influential groups perceive and act toward the possibilities of advancement within the their social landscape. Inherent within each category is an existing hegemony that serves its own interests above those who are less powerful in society. Within the context of this analysis, levels of education and educational practices are the pivotal role to be examined. Access to advanced training prepares human capital for greater levels of productivity and innovation, which serves the interests of the economic nation-state. The lack of it presents a cumulative effect that inhibits the attainment of greater levels of satisfaction on the part of members of the populace. This dissatisfaction brings with it reverberations that echo through the remaining eight categories of culture.

Combining the uneven distribution of wealth, control of capital, and cultural difference(s), an interesting portrait of the international landscape emerges, especially in the manner by which it impacts gender differences and education equity. Culture partially controls education in that it has a determining effect on what is valued and this value affects what may be studied or explored further. This means that men and women navigate the cultural and educational landscape in ways that are constantly interacting with one another. This interaction may be economic, political, gender-based, religious, traditional or progressive. These features and the characteristics of culture and interaction are influenced by social roles that various societies create and the increasing levels of complex interaction between its members, since interaction between different people occurs through the workplace, as well as socially. Because of the nature of this interaction, culture is in a state of semi-constant flux between the way it was and the direction in which it is evolving. Added to this are the forces or players that are prompting this social change. In that we are discussing education as a means to bettering ones self and so, by extension, the society in which that one lives, it is also being endowed with the same opportunities for self-determination. In this a choice can be made honestly. The legitimacy and honesty of making the choice to pursue some form of education or training because it is what one wants to do is a large part of what accounts for this state of social progress.

\subsection{Arab Human Development Report}

The 2009 Arab Human Development Report was published as a result of continuous research conducted in numerous Arab countries on the part of the United Nations and focused on a multitude of different areas including dimensions that were economic, social, political, and educational. This report is the result of a broad ranging analysis across countries in the 


\section{Al Macrothink}

Middle East and North Africa. While the report would certainly contain parts that may be contested, it nonetheless represents a serious information-gathering analytical effort by scholars from many different disciplines. Listed within this report were human development indicators. These indicators serve the function of illustrating the experience or opinion of less-powerful or disenfranchised groups. This pan-Arab inquiry spanned numerous countries and their cultures. The nature and purpose of the report is to provide greater understanding for the kinds of progress is both necessary and possible and the contributing factors in both of these areas. The belief in and attainment of education equity is often one of the fronts in this ongoing struggle. According to the AHDR, many of the respondents believe they are in need of their own 'Renaissance'.

The dimensions of this renaissance apply to numerous levels of society and included rights such as freedom of speech and expression, political affiliation, building a knowledgeable society, engagement and productivity in the workforce and, for the purposes of this analysis, the rise of women in society and its relationship to education.

It is important to note that not all Arab countries in the region participated in this survey, so this is not an exhaustive list. This can, however, be a litmus test for prevailing tendencies through the region. While there are some countries that are certainly more progressive with the social roles of men and women, it is possible to see where the fault lines occur between different elements of society, namely between traditional and progressive elements.

As can be seen from the 2005 Arab Human Development Report (p. 270-271), there is a high percentage of the population between these different countries that believe the rise of women is necessary for such a renaissance to occur. While not every nation provided data, those that did revealed very telling patters.

Table 1: Rise of Women Needed Across Various Societies (Arab Human Development Report, 2005, p. 270-271)

\begin{tabular}{l|c|c}
\hline Nations & \%-Yes & \&-No \\
\hline Algeria & -- & -- \\
Bahrain & -- & -- \\
Egypt & 88.70 & 6.20 \\
Iraq & -- & -- \\
Jordan & 86.06 & 10.31 \\
Kuwait & -- & -- \\
Libya & -- & -- \\
Mauritania & -- & -- \\
Morocco & 81.52 & 10.36 \\
Oman & -- & -- \\
Saudi Arabia & -- & -- \\
Sudan & -- & -- \\
Syria & -- & -- \\
Tunisia & -- & -- \\
Yemen & -- & -- \\
\hline
\end{tabular}




\section{$\Lambda$ Macrothink}

This table illustrates the percentage of the surveyed population that believes that women should hold more social power and influence.

The AHDR goes further in addressing the rights that women have to access and equity in education. Of the countries that provided data for analysis, including Jordan, Egypt, and Morrocco, upwards of $98 \%$ of the respondents were in agreement that women should have the same right to education at all phases, including university as men, regardless of age (p. 259-260). Regarding the right of a woman to choose her own specialty in university education, the percent of favorable response fell slightly, as illustrated in the table 2 .

Table 2: Right of Girls and Women to Choose Their Own University Specialization (AHDR, 2005, p. 261)

\begin{tabular}{l|c|c}
\hline Nations & \%-Yes & \&-No \\
\hline Algeria & -- & -- \\
Bahrain & & -- \\
Egypt & 90.20 & 8.10 \\
Iraq & -- & -- \\
Jordan & 85.67 & 12.02 \\
Kuwait & -- & -- \\
Libya & -- & -- \\
Mauritania & -- & -- \\
Morocco & 92.47 & 1.66 \\
Oman & -- & -- \\
Saudi Arabia & -- & -- \\
Sudan & -- & -- \\
Syria & -- & -- \\
Tunisia & -- & -- \\
Yemen & -- & -- \\
\hline
\end{tabular}

Table illustrates how many people believe that women should be able to choose their own course of study or training at the post-secondary level.

Despite the overall favorable opinion of the population(s) regarding the access and choice in education in the Arabic world, they "...remain poorly prepared to participate effectively and fruitfully in public life by acquiring knowledge through education (p. 73). While the acquisition of knowledge and the ability to advance one's standing in society enjoy a favorable opinion, there is a breakdown in how that experience actually plays out. It is interesting to observe this for two reasons: First, the Convention on the Elimination of All Forms of Discrimination against Women (CEDAW) is a document that was adopted, but with which a vast majority of the population is unaware. See table 3. 
Table 3: Percent of Respondents Aware of CEDAW (AHDR, 2005, p. 269)

\begin{tabular}{l|c|c}
\hline Nations & \%-Yes & \&-No \\
\hline Algeria & -- & -- \\
Bahrain & -- & -- \\
Egypt & 0.80 & 95.10 \\
Iraq & -- & \\
Jordan & 9.04 & 88.56 \\
Kuwait & -- & -- \\
Libya & -- & -- \\
Mauritania & -- & -- \\
Morocco & 10.65 & 87.19 \\
Oman & -- & -- \\
Saudi Arabia & -- & -- \\
Sudan & -- & -- \\
Syria & -- & -- \\
Tunisia & -- & -- \\
Yemen & -- & -- \\
\hline
\end{tabular}

Shows the percentage of the population that is aware of the United Nations Convention to End All Forms of Discrimination Against Women as illustrated by the Arab Human Development Report.

Secondly, a Millennium Goal held by the region relating to ending discrimination against women applies relates directly to the presence and empowerment of women in education at all levels (p. 71). This, in terms of a long-range investment in education, is one of the factors that help to bring about social and cultural pride, as well as economic parity. There are a variety of reasons this occurs and they are wide ranging. Data provided by the AHDR show that the enrollment of women at elementary, secondary, and tertiary levels in various areas of the Arab world exceeds that of men as a percentage of the population. "International data indicate that the girls in the Arab region perform better in school than boys" (p. 80). This assertion is represented by the percentage of girls, as opposed to boys, that scored higher on examinations in elementary school in both Bahrain and Kuwait. This applies to subjects such as math, English, science, Arabic, life skills and Islamic education. Girls are also less likely to drop out of school in the earlier grades. The completion of a fifth grade education in Algeria, for example, "exceeds 90 percent" (p. 80).

The literacy rates for various Arab countries yield data heavily suggesting that, as a group, the resources and capabilities of women are yet to be tapped. "Despite the tremendous spread of girls' education in Arab countries, women continue to suffer more than men do from a lack of opportunities to acquire knowledge" (p. 70). Countries that have worked to remedy this have implemented changes that do not come out even across the board. Thus, there are wide ranging differences as to the degree of literacy enjoyed by a total percentage of 


\section{Macrothink}

the population(s). The table below indicates, in spite of their presence in schools and advances that have been made, women lag behind men as a total percentage of men who are literate.

Table 4: Female Literacy Rate (Source: UNDP, HDR, 2009, Table 27)

\begin{tabular}{l|c}
\hline Nations & \% Literacy Rate (2005) \\
\hline Algeria & 95 \\
Bahrain & 97 \\
Egypt & 91 \\
Iraq & 81 \\
Jordan & 90 \\
Kuwait & 86 \\
Libya & -- \\
Mauritania & 72 \\
Morocco & 83 \\
Oman & 76 \\
Saudi Arabia & 79 \\
Sudan & -- \\
Syria & -- \\
Tunisia & 97 \\
Yemen & 63 \\
\hline
\end{tabular}

Shows the literacy rate of the total population of women.

The ADHR reports that there has been a substantial increase in the numbers of women in differing social roles within the Arab world. These range from journalism to teaching to different areas of the sciences. It is important to acknowledge these accomplishments since these increases have taken place in a fairly short period of time. The ADHR also reports that the expansion of women's presence in educational settings, as contributing members of society and as members and researchers in the sciences has increased, but as a percentage to the population of their male counterparts, is still far behind. Spratt (1992) also notes that, in the case of Morocco, improvement has certainly taken place, but notes that in spite of gains in literacy and workplace participation, women are still underrepresented in the workforce and in terms of attaining higher levels of education when compared with the percentage of men. Within the context of Morocco, Skalli (2001) goes further and states that this places women in a gendered mold within the workforce where the potential of mistreatment or abuse is literally factored into the possibilities present to them.

The implications of these conditions on women are numerous, adverse, and far-reaching: they include, but are not limited to, an increased pressure to work in the informal sector at all ages, 


\section{Ml Macrothink}

for longer hours, minimal wages, and a greater urgency to migrate within and outside the country in search of cash-earning activities some of which can be risky for their physical, mental, and psychological health. (p. 83)

The natural effect this situation has on any particular national economy is readily apparent in that it undercuts general social and economic progress through the absence or marginalization of educational opportunity as a whole. The avenue to success in the modern world lies with greater degrees of educational attainment. As noted by Al-Mahadin (2004), the progress made within the Arab world, while substantial, is counterbalanced by attitudes which are based on gender and have a determining effect as to what is possible or acceptable as to the further development of the individual. Were one to look at public educational expenditures between the Arab States and North America and Western Europe, it becomes apparent they are vastly under-spending on their students schooling in relation to the other developed countries of the world (UNESCO Institute for Statistics, 2007). This, when combined with overt gender imbalances, compounds the problem for the nation and region as a whole.

When looking at the issue from a still broader perspective and following the completion of school, there is the issue of participating in civic life. While there are many different ways that this happens, one of them is the place of women in governmental or ministerial positions. The AHDR (2009) reports that for nations involved in the Arab Spring, the percentage of women in governmental or ministerial positions was quite low.

Table 5: Percentage of Women in Government at Ministerial Level (AHDR, 2009, Table 29)

\begin{tabular}{l|c}
\hline Nations & \% \\
\hline Algeria & 2.4 \\
Bahrain & 8.7 \\
Egypt & 3.9 \\
Iraq & -- \\
Jordan & 10.7 \\
Kuwait & 0.0 \\
Libya & -- \\
Mauritania & -- \\
Morocco & 0.0 \\
Oman & 10.0 \\
Saudi Arabia & 0.0 \\
Sudan & 2.6 \\
Syria & 9.2 \\
Tunisia & 4.3 \\
Yemen & 4.1 \\
\hline
\end{tabular}

Shows how many women occupy positions of governmental authority as a percentage of the total population of government workers. 
The natural conclusion to this is that the lack of a female presence in larger number of public and/or governmental spheres presents an inhibitory result.

\section{Conclusion}

Globally competitive economies have initiated the changes required to have men and women positioned as viable and contributing members, not only within the labor force but also toward the development of new knowledge. It is only with this cumulative effort that any nation becomes a knowledge economy. The larger areas relevant here relate to nations that have not yet made this transition in their perception of gender equality and adjusted their social mores accordingly.

There is strength and needed uniqueness to the fact that cultures are quite similar, but also so very different. This is a feature of the human condition to be celebrated and elevated, but it also depends on how members within a particular culture tap into their own 'right to develop' (Tharoor, 1999/2000). More precisely, what do they have the right to tap into? In this lies the crucial difference between re-negotiating socialized gender roles towards advancement or exercising hegemonic influence in order to thwart that same advancement in order to retain the status quo. Thwarted or withheld, prolonged inequality can present grave consequences to collective advancement (Moghadam, 2002). In the context of the Arab region, it is important to note that progress has been made in these areas, but each version of the Arab Human Development Report makes clear that much work remains.

In the context of power transitions theory, a nation's relation to others with which they are in economic or other forms of competition will have the end results of building either satisfaction or dissatisfaction for members of their respective population(s). The total capacity, influence and subsequent power a nation comes to hold results from the efforts and capabilities of its workers collectively, and not just the ones that are male. As noted by Levin (1998, p. 8), “...the belief that economic progress hinges crucially on setting educational performance standards for the future 'information economy' is so strong that it needs no evidence to gain adherents." Countries that actively or passively, as a result of cultural norms, seek to thwart or marginalize the presence of female presence within avenues that comprise the institutions of learning or the workforce may pursue and succeed in maintaining their own particular cultural ends, but in relation to the international system, they are shortchanging the overall potential they have. This potential is both economic and social.

Writing for the New York Times, Thomas Friedman (2006) has observed that certain Arab states that realize their finite nature of their petroleum wealth are thinking toward the future. They are beginning to 'tap' their own people. As a result, they are becoming more competitive in relation to the productive means and capacity of their economies. This, in turn, is generating greater numbers of jobs with countries like Bahrain and Dubai of the United Arab Emirates. This is occurring at levels of knowledge production through increased levels of educational attainment. When a nation taps into and capitalizes on the human capital concept within their own people, this implies a substantial improvement in basic infrastructure and services like education. 


\section{$\Lambda$ Macrothink}

The Power Transitions framework of satisfaction versus dissatisfaction with either the national or international system is readily applicable here. This means the most efficient utilization of their human resources enable some to come out ahead both economically and politically of others. The dimension most important here is the economic. Raising the standard of living and sense of self-efficacy is a basic need common to groups seeking means beyond that of mere survival and subsistence. In the end, this also means that countries that refuse to utilize or recognize their resources in ways that are the most productive will become dissatisfied with the nature and hierarchy of the international order. The internal nature of this decision, or lack thereof, will cease to be an internal matter and manifest in their relationship with others. Inevitably, this will affect their relations with others on an international basis. Edward Said (2001) argues that individuals from different cultures have the instinctive tendency to interact with one another in a pragmatic fashion. His contention is that while there will always be differences in the social construction of culture, this does not and should not preclude people, including the political and policy-making circles of leadership, from adapting to changes which are realistic for and economically inter-dependent landscape.

Every country qualifies as needing to improve in the way it perceives all members of its society. There is no single nation that may claim exemption to this, but the systematic way much of the Arab world goes about maintaining and propagating these inequalities has resounding effects for educational equity. More importantly, these resounding effects will have their greatest effects on future generations of a semi-educated workforce. This is part of the direct result of the tension that exists between traditional and progressive elements of society. Inequality is not relegated strictly to available roles within the labor sectors, but also relates to the areas of research and development and the ability to generate indigenous knowledge bases. While this refers to levels far above the realm of primary or secondary education, they are naturally tied to it.

Education is an avenue that naturally leads to greater and greater degrees of satisfaction for a variety of reasons, among which raising the levels of economic competitiveness or standard of living are but two. The nature of this kind of global economic competition and resulting parity requires that more players be involved and in varying roles, and this necessitates a more involved and complex role for women in a global manner.

School is obvious as one of the primary agents of social change here. For this change to be envisioned and attempt to become effective, the equitable treatment of both sexes is a must across a much larger percentage of the population. Again, education helps to achieve satisfaction. Achieving this sense of satisfaction is a substantial part of what will further reinforce the benefits of peace among different nations and their cultures. Since the attainment of satisfaction is primarily an economic undertaking as it occurs between different countries, it stands to reason that the better the use of existing resources, the greater the return(s) for the effort. Achieving economic parity among nations also means raising a broader standard, including measures such as purchasing power, level(s) of education, opportunities for individual advancement, and cohesive social insurance that ensures equitable standing for all members of a culture or society. Addressing inequality within 
education, Stromquist (1990, p. 137) states that "the state emerges as a key actor regulating and promoting educational processes and outcomes."

As a result of the decision-making of different countries and cultures, not every group will not prioritize individual versus collective values in a uniform manner. Shashi Tharoor (1999/2000) makes this contention in describing rights as they relate to the idea of self-determinism and contrasting ideas of collectivism. Highly relevant is the manner by which nations utilize the means at their disposal to achieve better conditions for their people to live and prosper in. Navigating the differences between exploitation and the development of a greater pool of available talent occupy areas of challenge for any nation that finds itself in a process of growing, be it culturally, economically or otherwise. Women, as have been shown in the world and through this analysis, represent the strength of another entire arm added to the potential of the one-armed individual, not to mention an additional hemisphere to the brain. Cultural groups and their members who deny this do the disservice of not reaping all they are capable of with regard to benefits that come as a result of participation in international economics.

As the Arab Spring remains to run it's course, either in the short or long term, the societies that are remaking themselves politically will inevitably do so culturally and socially as well. As they confront the challenges that accompany transition as is currently happening in Egypt, the questions of gender roles will present themselves. While each nation may have a different set of answers to these questions, they would do better not to ignore them, but instead address them in a way that illustrates a deeper understanding of a highly interdependent and globalized world context. For a country to steadfastly situate itself within traditions or practices that are not open to the possibility of discussion or refinement takes away the other strong arm that could have been.

\section{References}

Al-Mahadin, S. (2004). Jordanian women in education: Politics, pedagogy and gender discourse. Feminist Review, 78, 22-37. http://dx.doi.org/10.1057/palgrave.fr.9400188

Arab human development report. (2005). Towards the rise of women in the Arab world. (May, 2007). Reference and Research Book News, 22(2). Retrieved February 22, 2008, from Research Library database. (Document ID: 1284128151).

Arab human development report. (2009). Challenges to human security in the Arab countries. (May, 2007). Reference and Research Book News, 22(2). Retrieved October 31, 2011, from http://www.arab-hdr.org/contents/index.aspx?rid=5

Baronov, D. (2004). Conceptual foundations of social research methods. Boulder: Paradigm Publishers.

Benavot, A. (May, 1992). Curricular content, educational expansion, and economic growth. Comparative Education Review, 36(2), 150-174. http://dx.doi.org/10.1086/447097 
Bradshaw, Y., \& Wallace, M. (1996). Global inequalities. Thousand Oaks.

Burtless, G. (June, 1995). International trade and the rise in earnings inequality. Journal of Economic Literature, 33(2), 800-816.

Cummings, W. (March, 1995). The Asian human resource approach in global perspective. Oxford Review of Education, 21(1), 67-81. http://dx.doi.org/10.1080/0305498950210105

Douglas, S. (1995). Where the girls are: Growing up female with the mass media. New York: Three Rivers.

Friedman, T. (2006). The world is flat. New York: Farrar, Strauss and Giroux.

Hunt, S., \& Posa, C. (1997). Women Waging Peace. Robert Jackson (Ed.) Global Issues 02/03. $18^{\text {th }}$ ed. (pp. 200-205). Guilford: McGraw-Hill/Dushkin.

Ilon, L. (1998). The effects of international economic trends on gender equity in schooling. International Review of Education, 385-356. http://dx.doi.org/10.1023/A:1003217807277

Jones, P. (1997). The world bank and the literacy question: Orthodoxy, heresy and ideology. International Review of Education, 43(4), 367-375. http://dx.doi.org/10.1023/A:1003079907431

Leach, F. (1998). Gender, education and training: An international perspective. Gender and Development, 6(2), 9-18. http://dx.doi.org/10.1080/741922727

Levin, H. (May, 1998). Educational performance standards and the economy. Educational Researcher, 27(4), 4-10.

Marquadt, M. \& Engel, D. (1993). Global human resource development. Upper Saddle River: Prentice Hall.

Millennium Summit Multilateral Treaty Framework. Convention on the Elimination of All Forms of Discrimination against Women, 18 December 1979. http://untreaty.un.org/English/millennium/law/index.html. Retrieved 18 November 2003.

Mitter, S. (1999). Globalization, technological changes and the search for a new paradigm for women's work. Gender, Technology and Development, 3 (1), 1-17. http://dx.doi.org/10.1177/097185249900300101

Moghadam, V. (Summer, 2002). Islamic feminism and its discontents: Toward a resolution of the debate. Signs, 27(4), 1135-1171. http://dx.doi.org/10.1086/339639

Said, E. (2001). The Clash of Ignorance. Robert Jackson (Ed.) Global Issues 02/03. 18th ed. (pp. 11-14) Guilford: McGraw-Hill/Dushkin.

Schneider, L., \& Silverman, A. (2003). Global sociology: Introducing five contemporary societies ( $3^{\text {rd }}$ ed.). Boston: McGraw-Hill.

Skalli, L. (Winter, 2001). Women and poverty in Morocco: The many faces of social 


\section{Macrothink}

International Journal of Education

ISSN 1948-5476

2012, Vol. 4, No. 1

exclusion. Feminist Review, 69, 73-89. http://dx.doi.org/10.1080/014177800110070120

Spratt, J. (March, 1002). World literacy in the year 2000. Annals of the American Academy of Political and Social Sciences, 520, 121-132.

Stromquist, N. (1990). Gender inequality in education: Accounting for women's subordination. British Journal of Sociology of Education, 11(2), 137-153. http://dx.doi.org/10.1080/0142569900110202

Tammen, R., Lemke, D., Alsharabati, C., Efird, B., Kugler, J., Stam, A., Abdollahian, M., \& Organski, A. (2000). Power transitions: Strategies for the $21^{\text {st }}$ century. New York: Chatham House.

Tharoor, S. (2001). Are human rights universal? Robert Jackson (Ed.) Global Issues 02/03. 18th ed. (pp. 187-190) Guilford: McGraw-Hill/Dushkin.

UNESCO Institute for Statistics. (2007). Global education spending concentrated in a handful of countries. http://www.uis.unesco.org/template/pdf/EducGeneral/Factsheet07_No3_EN.pdf. Retrieved September 24, 2008.

United Nations. (2006). Arab human development report: Toward the rise of women in the Arab world.

Waltz, K. (1979). Theory of international politics. New York: McGraw-Hill.

Waltz, K. (1986). Political structures. In R. Keohane (ed.) Neorealism and its critics (pp. 70-97). New York: Columbia University Press.

\section{Glossary}

P-T Theory: Power Transition Theory

\section{Copyright Disclaimer}

Copyright reserved by the author(s).

This article is an open-access article distributed under the terms and conditions of the Creative Commons Attribution license (http://creativecommons.org/licenses/by/3.0/). 